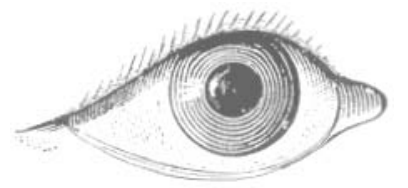

Rosaura García Ramos

Jefa del Servicio de Restauración de la Diputación Foral de Álava

\title{
EXAMEN MATERIAL DE LA OBRA DE ARTE, LA CORRESPONDENCIA DE POLICROMÍAS
}

\section{Introducción}

Desde los inicios de la historia de la Restauración de Obras de Arte y hasta comenzado el siglo XX, se presta una especial atención a la restauración de pintura, considerándose la escultura un arte menor y siendo ésta objeto de intervenciones poco ortodoxas en comparación con los criterios seguidos paralelamente en el tiempo para la restauración de pinturas.

Es a mediados de este siglo, en Austria y Alemania, cuando los técnicos en restauración comienzan a mostrar un destacado interés por el estudio de las policromías originales. Posteriormente se llevan a cabo las primeras restauraciones científicas en los talleres del IRPA (Instituto Real del Patrimonio Artístico) de Bruselas, cuando aún se encontraban en los sótanos de los Museos Reales de Arte e Historia de esa ciudad. Es en esta época, bajo la dirección de Agnés Ballestrem, cuando se comienzan a realizar los primeros exámenes de estratos policromos, siguiendo un riguroso método arqueológico, basado en el estudio detallado de las capas que componen cada una de las policromías existentes en una obra.

Este estudio detallado de los componentes materiales de la obra revela el estado de conservación de los mismos, los deterioros que sufren y sus causas, las sucesivas intervenciones, los cambios y añadidos históricos que presenta la obra, los usos que de ella se han hecho, las técnicas de su fabricación o elaboración, incluso en algunos casos, su autenticidad o falsedad, ya sea ésta total o parcial. Parte de este estudio se centra en el análisis y determinación de las capas de cada policromía, que da como resultado un gráfico con las correspondencias de las mismas, es decir su orden cronológico y la superficie que ocupan, ya que no todas las policromas superpuestas, o repolicromías, son generales, a veces sólo se repolicromaban algunas partes de la imagen.

Este examen es de gran importancia e incide de manera muy especial en la elaboración de la historia material de la obra y su conocimiento desde el punto de vista de la Historia del Arte.

\section{Estudio de Correspondencia de Policromías}

El hecho de que nos encontremos tan a menudo con esculturas que presentan varias policromías superpuestas se debe a que este tipo de piezas, en especial las imágenes de culto, ha sido objeto de numerosos cambios a través de los tiempos, ya fuese por los dictámenes de la moda o para mantenerlas en "buen uso".

La ausencia de un examen preliminar detallado, absolutamente necesario, ha dado lugar a numerosos atentados contra la obra, atentados que desgraciadamente se siguen cometiendo en la actualidad, cuando se eliminan policromías superpuestas de forma inconsciente o se llevan a cabo reintegraciones que no se atienen a ningún nivel en concreto, por ignorar la correcta sucesión cronológica de policromías, creando en la obra una confusión óptica y una apariencia estética que no se corresponde con ninguno de sus momentos históricos.

Por otra parte, la falta de criterios éticos ha motivado que en muchas ocasiones se hayan considerado estas capas de policromías superpuestas como repintes. El no valorarlas como capas "originales" ha favorecido que hayan sido eliminadas sistemáticamente, sin tener en cuenta su valor histórico, artístico y documental.

Estas eliminaciones se han realizado con frecuencia sin los medios necesarios y sin el auxilio de la técnica, por lo que nos encontramos a veces con policromías originales realmente masacradas.

En otras ocasiones, la falta de coherencia a la hora de eliminar determinadas policromías superpuestas ha tenido como consecuencia la creación de "falsos históricos", es decir piezas que muestran un conjunto de policromías parciales de distintas épocas y cuya apariencia no se corresponden con ningún periodo histórico.

Por otro lado, también se observa una mayor discriminación con respecto a ciertos periodos artísticos, ya sea por parte de historiadores o restauradores, como es el caso del Neoclásico o el Neogótico, lo que ha provocado que casi no queden policromías representativas de los mismos.

La justificación de estas actuaciones es más que dudosa. Si intentamos definir los términos policromía, repolicromía y repinte, en los que se encuentra trabajando el Grupo Latino de Trabajo sobre Escultura Policromada, basándonos en los más serios criterios de respeto hacia todo legado histórico y artístico, entenderemos por policromía la capa o capas de 
color, con o sin preparación, realizada con distintas técnicas (temple, óleo, emulsiones, etc.) y motivos decorativos (incisiones, punzonado, cortaduras, hojas metálicas, incrustaciones, etc.), que recubre total o parcialmente relieves, esculturas y ciertos elementos arquitectónicos, mobiliario, etc., con el fin de proporcionar a estos objetos un acabado o decoración. La policromía es consustancial a los mismos y forma parte indivisible de su concepción e imagen: la repolicromía, debe ser considerada como una renovación, puesta al día o matización de estos objetos, con intención de conferirles un nuevo uso o de adaptarlos a los gustos de la época. Se trata también de una policromía original, perteneciente a un momento histórico diferente al de la concepción del objeto policromado, total o parcial, cuya elaboración responde a las mismas características de los métodos y técnicas de la época a la que pertenece. Por ello ha de ser entendida como un elemento natural que forma parte consustancial de la pieza y de su evolución histórica y que en principio debe constituir un elemento a conservar, como incluso queda establecido en la Ley 16/1985 de 25 de junio del Patrimonio Histórico Español, en su Artículo 39.3, que dice:

"Las restauraciones de los Bienes a que se refiere el presente Artículo respetarán las aportaciones de todas las épocas existentes. La eliminación de alguna de ellas sólo se autorizará con carácter excepcional y siempre que los elementos que traten de suprimirse supongan una evidente degradación del Bien y su eliminación fuera necesaria para permitir una mejor interpretación histórica del mismo. Las partes suprimidas quedarán debidamente documentadas".

El repinte, sin embargo, "es una intervención, total o parcial, realizada con la sola intención de disimular u ocultar daños existentes en la policromía, imitándola $\bigcirc$ transformándola. Técnicamente difiere de las características técnicas de la policromía que pretende reparar, no respeta los límites de la laguna y no suele tener intención de cambiar o actualizar la decoración del objeto".

Es fundamental no confundir repinte y repolicromía, y ante los abusos que en la práctica se han venido cometiendo, conviene reivindicar el valor histórico, artístico y documental de esta última.

Para el correcto conocimiento de estas policromías, se ha desarrollado una técnica que permite el estudio de su correspondencia, sin la necesidad de eliminar ninguna de ellas. Esta técnica está basada en los mismos principios que rigen el estudio de los estratos en las excavaciones arqueológicas.

\section{Técnica de Correspondencia de Policromías}

En primer lugar conviene decir que el "estudio de correspondencia" no se debe llevar a cabo cuando no se dispone de los medios necesarios o se carece de la experiencia y conocimientos sobre esta técnica, ya que se podrían provocar daños irrepara- bles o llegar a unas conclusiones erróneas que podrían alterar posteriores estudios sobre la obra.

También es conveniente juzgar hasta qué punto es necesario y adecuado llevar a cabo un estudio de estas características, sobre todo en aquellas piezas que, por su buen estado de conservación, no presenten deterioros como lagunas o craquelados que permitan la observación de los estratos. Conviene determinar también qué piezas se destinarán a este tipo de estudios, ya que el número de horas que se necesitan para su realización es sumamente elevado, de ahí que sea tan costosa su realización. En cualquier caso, es evidente que para llevarlo a cabo se ha de tener la certeza de que la obra tiene más de una policromía, es decir que existen policromías subyacentes. El análisis de las policromías debe evitar al máximo las intervenciones destructivas: para ello se han de aprovechar las lagunas existentes, realizando "ventanas de estudio" sólo en caso de que sea absolutamente necesario. Estas han de ser de un tamaño mínimo, tan sólo unos milímetros, y localizarlas en bordes de lagunas y en lugares determinantes pero lo más ocultos posible, para lo que es necesario contar con el equipamiento adecuado.

\subsection{Objetivos}

La información que se pretende obtener cubre dos objetivos básicos. En primer lugar conocer la evolución en el tiempo de la pieza, los usos que de ella se han hecho, su adaptación a los dictámenes de la moda, etc., Ilegando, si es posible, a reconstruir gráficamente cada policromía.Y en segundo lugar, recoger la mayor cantidad de datos posibles para el mejor conocimiento de la evolución de las técnicas de policromía a lo largo de la historia, de los motivos decorativos, etc. A estos objetivos se llega mediante la determinación de:

- Número de policromías.

- Número de estratos de cada policromía.

- Localización y extensión de cada una de ellas.

- Técnica de ejecución de cada una de ellas.

- Tipo de decoraciones.

- Características como textura, porosidad, etc.

- Estado de conservación.

- Datación absoluta o relativa.

Esta información puede utilizarse a la hora de eliminar alguna de las policromías, pero éste no es el objetivo del estudio. La decisión de eliminar alguna de ellas es una cuestión de criterios específicos que se analizarán más adelante.

\subsection{Aplicación de la técnica}

El proceso de trabajo consta de cinco fases sucesivas que se van complementando:

a. Examen preliminar

b. Examen al microscopio

c. Análisis de laboratorio

d. Elaboración de la carta de correspondencias

e. Reconstrucción gráfica de policromías

\author{
La ausencia de un \\ examen preliminar \\ detallado, absolutamente \\ necesario, ba dado lugar \\ a numerosos atentados \\ contra la obra, atentados \\ que desgraciadamente se \\ siguen cometiendo en la \\ actualidad
}




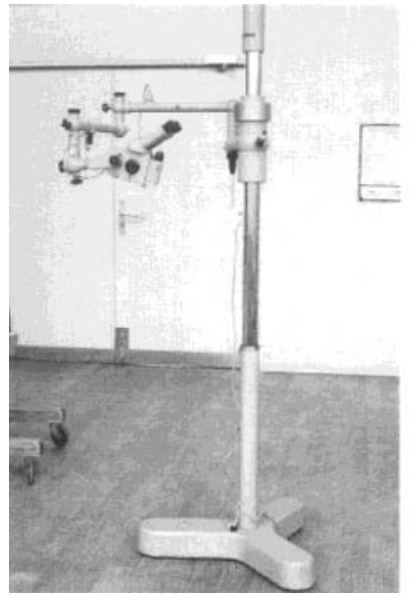

Fotos 1 y 2

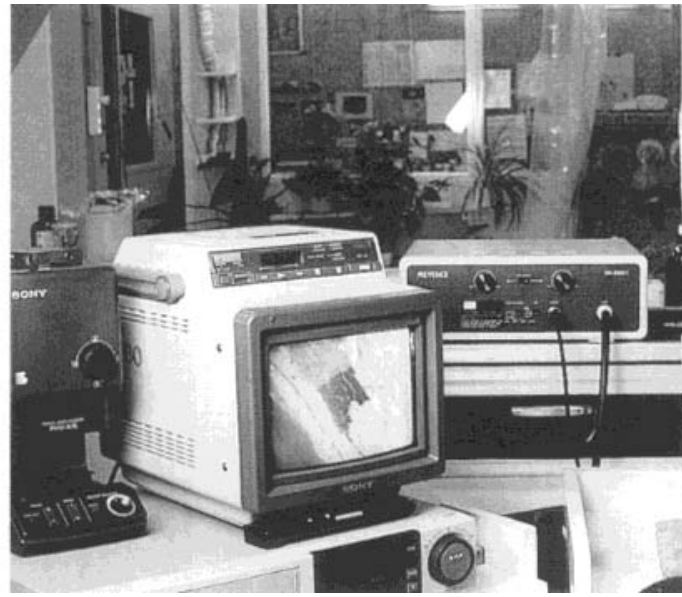

\section{2.a. Examen preliminar}

Esta primera fase consiste en la observación minuciosa y detallada de la obra. Se ha de revisar su superficie, la presencia de lagunas de interés, grietas, existencia de policromías subyacentes, etc. Es conveniente ya desde esta fase comenzar una documentación fotográfica detallada.

Los resultados obtenidos determinarán la necesidad o no de continuar el estudio en sus diferentes fases, en función de la existencia de una o más policromías, de su localización y de su extensión.

Una vez que se ha decidido continuar con el estudio en profundidad, es necesario determinar con exactitud las zonas a examinar, evitando así las incursiones indiscriminadas por la geografía de la pieza. Estas zonas han de estar situadas en lugares estratégicos, como:

- zonas de intersección entre los distintos elementos decorativos de la talla (cabello-carnación, manto-túnica, manto-carnación, pie-peana, etc.).

- zonas de cambio (paso de un color a otro, de una superficie lisa a otra decorada, de una técnica a otra, etc.).

- bordes de determinadas lagunas.

La correcta elección de estas zonas reducirá al mínimo la realización de ventanas, favorecerá la exactitud de los resultados y tendrá una importante repercusión en la elaboración de la carta de correspondencias y en la reconstrucción de las policromías subyacentes.

Para ello se elegirán lugares poco visibles y siempre que sea posible en zonas profundas o protegidas, que son las que guardan el mayor número de capas por estar menos expuestas a los roces y agresiones. Tras la observación minuciosa se habrán de realizar una serie de croquis donde se reflejen los lugares precisos a estudiar y que servirán de guía para el examen al microscopio. Los puntos elegidos se identificarán mediante una clave numérica y la descripción del mismo (ver gráfico número I).

Con posterioridad a la realización de estos gráficos

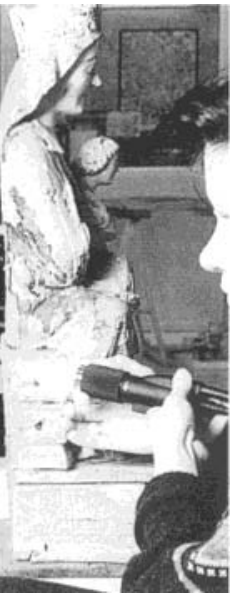

es necesario llevar a cabo un examen completo de la policromía superficial, recogiendo el mayor número de datos posibles sobre sus características (porosidad, textura, número de estratos, técnica, etc.).

Este es el momento de determinar el estado de conservación de las policromías, lo que nos indicará la necesidad o no de realizar un tratamiento fijación de las mismas, antes de pasar a la siguiente fase. Ya que si existen levantamientos, falta de adhesión entre estratos o de cohesión en los mismos no se podría trabajar sin riesgo sobre la pieza, realizando, por ejemplo, la limpieza de suciedad superficial o cualquier resto de depósito ajeno a la policromía.

\section{2.b. Examen al microscopio}

Siguiendo los puntos de observación preestablecidos en los croquis de la fase anterior, se comienza el examen de cada uno de ellos. Este ha de realizarse al microscopio binocular y, si se dispone de él, con la ayuda del vídeo-microscopio de exploración (fotos I y 2).

Estos aparatos permiten trabajar con unos aumentos que pueden oscilar entre $16 x$ y $1.000 x$. Lo que posibilita la exhaustiva exploración de los diferentes estratos, incluso la más fina de las capas y las características de cada una de ellas (colas, capas de color, número de estratos de la preparación, texturas, brillo, transparencia, tipo de granos de los pigmentos, desgastes, etc.)

La posibilidad de contar con un gran número de aumentos en el vídeo-microscopio permitirá evitar parte de la toma de muestras para la realización de estratigrafías en el laboratorio, reduciendo los análisis destructivos al máximo.

No obstante, hay que decir que presenta cierta dificultad para acceder a algunas zonas recónditas y que su manejo resulta laborioso cuando se trata de estudiar una escultura, ya que es casi imposible fijarlo a un soporte y depende absolutamente de la mano del restaurador, con el consiguiente movimiento provocado por ésta. Otras ventajas de este equipo son la posibilidad de grabar las imágenes y la observación de éstas en un monitor, haciendo el trabajo menos fatigoso y permitiendo que la misma imagen pueda ser vista y analizada por varios técnicos a la vez. Aparte de estos aparatos, se necesita el siguiente material:

- Bisturí de cuchilla recambiable, de un acero que permita el afilado de la hoja sin provocar rebabas que puedan dañar los estratos durante el trabajo. Son muy adecuados los utilizados en microcirugía y en cirugía de huesos, por la dureza, tamaño y durabilidad de las cuchillas. 
- Acuarelas y pinceles, para realizar gráficamente y a color las estratigrafías de las diferentes policromías que se vayan examinando.

- Esencia de petróleo o, en su defecto, W. Spirit, para refrescar las zonas de estudio y poder ver con claridad las superficies de los distintos estratos.

- Bastoncillos de algodón, de madera, y pincel fino para limpiar las zonas en proceso de estudio.

- Realización de macro-fotografías.

- Toma de imágenes en vídeo, lo que permitirá el examen de los diferentes puntos por varios técnicos simultáneamente.

En primer lugar se procede a la observación y examen de las lagunas elegidas en los croquis anteriores; no obstante, si estos puntos no son suficientes para completar el estudio de las distintas policromías, es necesario comenzar con la abertura de las "ventanas" detalladas también en dichos croquis.

Estas ventanas han de ser de tamaño mínimo, $3 \times 7$ ó $10 \mathrm{~mm}$ aproximadamente, y deben también estar situadas en los lugares más estratégicos y menos visibles.

Se deben realizar con bisturí, con un mínimo de 50 aumentos, ya que con menos aumentos se corre el peligro de que algún estrato pase desapercibido, y deben abrirse dejando al descubierto cada uno de los estratos que forman las diferentes policromías, incluso aunque se trate de una fina capa de cola, (foto 3). Durante la observación al microscopio, es necesario reflejar detalladamente por escrito los siguientes datos:

- Número de estratos y estado de conservación de cada uno de ellos.

- Existencia de veladuras superficiales, su estado de conservación, color, dureza, grosor, transparencia, etc.

- Color, tipo, tamaño y distribución de los diferentes granos de pigmentos.

- Presencia de elementos decorativos, tales como estrellas, brocados, brocados aplicados, estofados o cualquier otro elemento decorativo, etc.

- Preparación, número de capas que la componen, textura de cada una de ellas, color, presencia de capas intermedias de aislamiento y sus características.

- Telas de refuerzo o utilizadas como base para la preparación.

Todo ello debe reflejarse mediante gráficos, con el máximo de anotaciones posibles, de cada una de las zonas observadas. Dichos gráficos deben llevar la identificación del lugar examinado (Gráfico I).

Es importante tener en cuenta que para realizar un estudio de este tipo, sin errores en las afirmaciones, es necesario que el restaurador posea la suficiente experiencia en este campo, como para que le permita establecer las semejanzas o diferencias de textura, grosor, dureza, porosidad, brillo, etc. de los estratos de los distintos puntos observados, independientemente del nivel que éstos ocupen en cada uno de los puntos examinados. Esta labor es difícil, ya que en la mayor parte de los casos las piezas presentan repolicromías parciales a las que se superponen otras totales, o viceversa. Por ello se suele encontrar en unas zonas un número de policromías distinto al de otras y el restaurador deberá, en estos casos, relacionarlas adecuadamente. En esta fase se pueden establecer ya algunas hipótesis sobre la datación relativa de cada una de las policromías.

Por otro lado, un técnico experimentado puede llegar a veces a identificar ciertas técnicas o pigmentos característicos de periodos concretos, lo que facilitará la datación absoluta.

\section{2.c. Análisis de Laboratorio}

A veces, cuando hay dudas o los datos obtenidos del estudio anterior no son suficientes para determinar los materiales o las capas que componen una estratigrafía, es necesario recurrir a la toma de muestras para la realización de análisis propios del laboratorio (en este punto hay que señalar que en raras ocasiones, cuando el número de policromías es importante, se consigue obtener una muestra con todos los estratos, ya que por lo general se suelen romper o separar al intentar tomarla).

Para ello también hay que determinar con exactitud las zonas de donde han de tomarse dichas muestras, de manera que sean lo más útiles posible y no exista ningún problema para identificarlas posteriormente. Es evidente que hay que huir de la toma indiscriminada de las mismas y que no se deben llevar a cabo por el sólo hecho de satisfacer la curiosidad de cada uno. La toma de muestras, ya que se trata de un tipo de análisis destructivo, ha de estar debidamente justificada.

En estos casos es el restaurador el que mejor sabrá elegir los puntos de muestreo, dado que es el que ha llegado, tras las fases anteriores, a un mejor conocimiento de la geografía de la obra y podrá determinar de dónde se pueden extraer todas las capas deseadas, con el mínimo riesgo de exfoliación o rotura alguna.

\section{Foto 3}

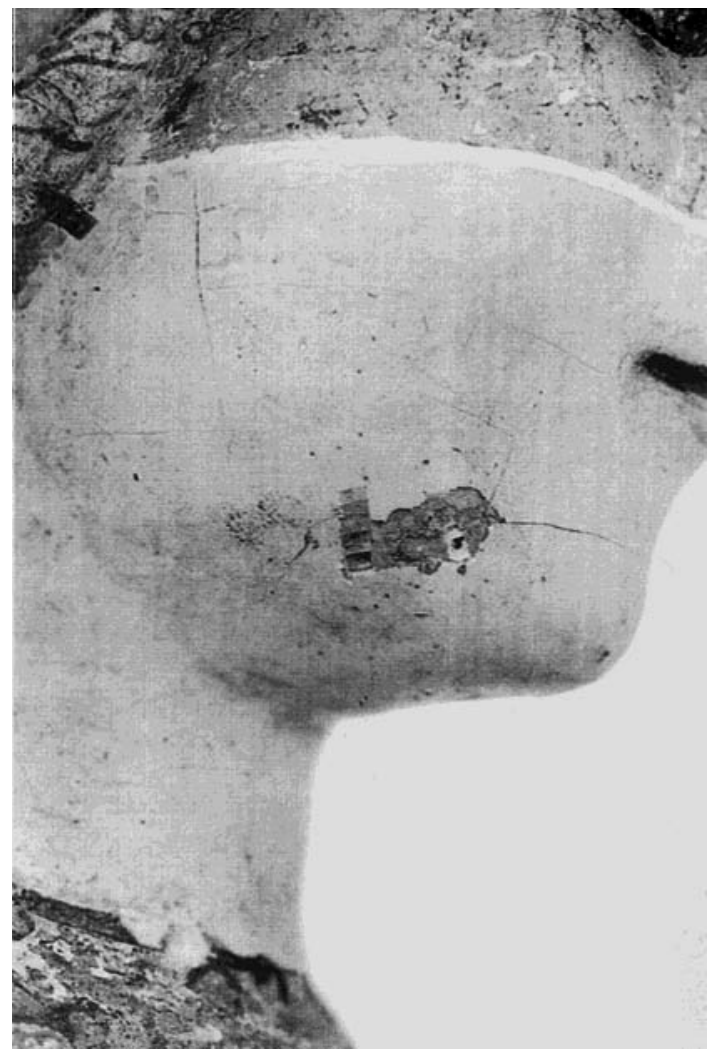




\section{Gráfico 1. Busto relicario de Santa (talla flamenca}

\section{Z Zona quemada Linea de separación de piezas \\ 1,2 Zonas estudiadas al etc microscopio}

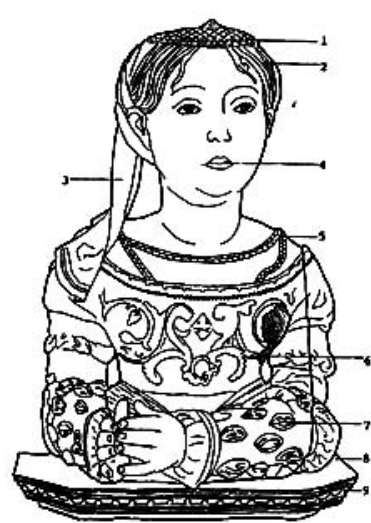

Gráfico 2 Esta tabla se puede ampliar en dos sentidos, en sentido vertical, para las diferentes policromías subyacentes que existen y, en sentido borizontal, para las diferentes zonas por estudiar, basta con repetir las diferentes casillas o líneas, dependiendo de los casos
TABLA DE CORRESPONDENCIAS DE POLICROMÍAS

\begin{tabular}{|c|c|c|c|c|}
\hline SIGLO & \multicolumn{3}{|c|}{ ZONA ESTUDIADA } & ZONA ESTUDIADA \\
\hline ம் & 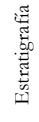 & 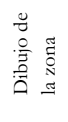 & $\begin{array}{c}\text { Descripción de } \\
\text { la estrategia }\end{array}$ & \\
\hline 站 & & & & \\
\hline लें & & & & \\
\hline 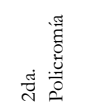 & & & & \\
\hline 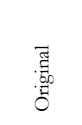 & & & & \\
\hline
\end{tabular}

Cada policromía, con todos sus estratos, ocupará un nivel, por lo tanto habrá tantos niveles como policromías presente la talla.

Partiendo del muestreo completo, se puede establecer igualmente la localización y extensión de cada una de las policromías y a partir de que cada nivel corresponde a un periodo y una fecha concreta se consigue establecer la cronología relativa de cada policromía (Gráfico 2).

Por otro lado, de la información que aparezca reflejada en documentos de época, de las características estilísticas o técnicas propias de fechas concretas, etc., se podrán establecer cronologías absolutas.

La realización de la carta permite tener una visión de conjunto bastante esclarecedora. Estableciéndose las diferentes policromías y en qué periodo se han realizado intervenciones totales o sólo parciales.

Tras la preparación y observación al microscopio de las correspondientes estratigrafías y láminas delgadas y la realización de los análisis de laboratorio que sean necesarios (sencillos, como tinciones, que pueden ser hechos por el mismo restaurador o más complejos, como cromatografía, espectrometría infrarroja, difracción de rayos $X$, etc., a efectuar por químicos especializados en la materia) se pueden obtener datos de gran interés, como:

- Aglutinantes empleados (oleosos, proteicos, etc.).

- Identificación exacta de los pigmentos.

- Identificación de las lacas y origen de las mismas (vegetal o animal).

- Tipo de carga utilizada en la preparación.

- Presencia de capas de aislamiento.

- Grosor en micras de cada uno de los estratos. - Etcétera.

De los resultados de dichos análisis se debe elaborar la correspondiente documentación, es decir las fichas de descripción de las estratigrafías y macrofotografías de las muestras con diferentes tipos de aumentos y de luz. Esta documentación se adjuntará al dossier del estudio que se está realizando de la obra.

\section{2.d. Elaboración de la carta de correspondencias}

Para la elaboración de las conclusiones del estudio es necesario comparar todos los muestreos efectuados y a partir del resultado de estas comparaciones se construye la carta de correspondencias. La carta tiene una estructura de trama a partir de dos ejes. En el superior se reflejan los puntos estudiados y en el izquierdo la distribución por niveles de las policromías examinadas.
A partir de esta visión global, se pueden a veces llegar a algunas hipótesis de tipo histórico, como por ejemplo si las modificaciones han coincidido con fechas en las que se han producido cambios litúrgicos, estilísticos, etc.

También se pueden deducir situaciones económicas, ya que las tareas de policromado suponían unos gastos mayores o menores en función de la extensión de la intervención y de la calidad de los materiales empleados.

Si una pieza presenta numerosas policromías superpuestas y las subyacentes están en relativo buen estado de conservación, puede inducir a pensar que se trata de una imagen de gran devoción, que se ha ido poniendo al día periódicamente.

Desde el punto de vista técnico, es especialmente interesante la constatación del uso de los distintos materiales y técnicas cronológicamente. A partir de esta información y contando con los tratados existentes al respecto, se puede ir estableciendo una Historia de las Técnicas de la Policromía bastante fiable y científica.

Por otro lado se pueden obtener datos de interés para la Historia del Arte. En especial si se pueden comparar estudios de correspondencias de distintas piezas de una misma región. Así reconocería la actividad de ciertos talleres, qué estilos han tenido una mayor incidencia en la zona, en qué medida la región estudiada ha estado influenciada por las diferentes corrientes estilísticas, etc.

Todas estas conclusiones e hipótesis deben quedar reflejadas por escrito, siendo necesaria la colabora- 
ción de especialistas en la materia para las cuestiones históricas y estilísticas.

\section{2.e. Reconstrucción gráfica de las policromías}

Una vez finalizada la carta de correspondencias, que nos habla de las distintas policromías, de su localización y extensión, podemos proceder a la reconstrucción gráfica de cada una de ellas. Para ello, sobre un croquis de la talla, de una o varias de sus vistas, podemos realizar gráficamente réplicas de las distintas policromías que ésta posee. Esto se puede llevar a cabo manualmente o mediante ordenador, con un programa de tratamiento de imagen.

En aquellas ocasiones en que se plantee la posibilidad de eliminar alguna repolicromía, la comisión fundada a tal efecto puede reflexionar sobre su conveniencia o no, en base a la información aportada por el estudio de correspondencias, sin olvidar nunca las cuestiones legales y de criterios. Este tipo de documentación contribuye a evitar en numerosas ocasiones los levantamientos de policromías, ya que permite conocer los distintos estados de la obra sin que esta clase de intervenciones sean necesarias, bien porque se hayan obtenido los datos suficientes como para documentarla gráficamente, bien porque se demuestre que el porcentaje que se conserva de la/s policromía/s subyacentes, la dificultad o el coste que ello supone lo desaconseja. Por otro lado constituyen siempre un documento de gran utilidad didáctica, ya sea desde el punto de vista de la historia del arte o desde el punto de vista técnico.

Conviene decir, sin embargo, que no siempre se cuenta con los datos suficientes como para realizar reconstrucciones exactas, ya que en muchas ocasiones se trabaja con hipótesis, no pudiendo, por ejemplo, reconstruir las policromías con todas sus decoraciones, bien por desconocer los motivos decorativos con exactitud o por no poder establecer la localización y extensión de los mismos, como puede ocurrir con la policromía de un manto o con la de un rostro, donde no sabemos, la mayoría de las veces, cómo era el dibujo de los ojos, cejas, etc. y donde sólo conocemos los colores y las características materiales de ésta.

En algunos casos ni siquiera es factible realizar- una reconstrucción parcial de la policromía de ciertas zonas. Tampoco cuando se realiza una eliminación de policromías se obtienen siempre policromías subyacentes completas. En numerosas ocasiones se han perdido total o parcialmente sus decoraciones o partes importantes de esas policromías.

Para mejor comprensión de lo antes dicho, se puede examinar el catálogo Barroco Importado en Álava. Escultura y Pintura, publicado por la Diputación Foral de Álava, Vitoria, 1995, en concreto las fotografías de la Virgen del Rosario, de Lezama, Álava, en las páginas 169 (estado actual) y 358 (policromía subyacente) y de la Inmaculada Concepción de la
Iglesia de Santa María de Salvatierra, Álava, en las páginas 197 (policromía actual) y 359 (policromía subyacente).

\section{Conclusión}

Como hemos visto anteriormente, la ley y otros documentos internacionales, como la Carta de Venecia, el Código Deontológico de la profesión y numerosos escritos sobre criterios aceptados internacionalmente, protegen la obra de arte y sus añadidos históricos.

Esta protección incluye las policromías superpuestas, o repolicromías, por lo que en la mayoría de los casos eliminarlas puede constituir un atentado contra el Patrimonio.

La decisión de eliminar una o varias policromías deberá ser meditada y justificada convenientemente, no debe hacerse nunca en función únicamente de la opinión del restaurador, sino que ha de ser tomada por una comisión de especialistas en Arte y en Restauración, creada a tal efecto. De todos modos hay que tener en cuenta que este tipo de intervenciones suponen un elevado número de horas de trabajo, lo que se traduce en un coste muy alto para la restauración de la pieza; por ello es necesario, antes de llegar a esta decisión, realizar una estimación del gasto y del tiempo a emplear, para posteriormente ver si la intervención será rentable a todos los niveles, ya que es evidente que nuestro patrimonio es tan extenso y existen obras en tan mal estado, que cualquier derroche de dinero y tiempo a favor de una pieza, va en detrimento de la conservación de otras.

Sin embargo no hay por qué renunciar al conocimiento de las policromías subyacentes; por ello, la opción lógica es recurrir al estudio de correspondencias, dado que se trata de un método científico, basado en unos criterios y metodología de trabajo específicos y cuyos resultados, siempre y cuando este estudio se haga de forma correcta, son totalmente fiables.

En cualquier caso, si definitivamente se toma la decisión de levantar una policromía, se deberá encargar el trabajo a personal especializado que pueda disponer del equipamiento necesario para llevarla a cabo con las suficientes garantías de conservación y respeto para la policromía que subyace y que quedará al descubierto.

Finalmente el restaurador deberá tomar, gráfica y fotográficamente, todos los datos posibles sobre las zonas y capas a eliminar, de forma que el testimonio histórico que va a desaparecer quede debidamente documentado para posteriores estudios o consultas.

\section{BIBLIOGRAFIA}

PERIER-D IETEREN, Catheline. La Restauration en Belgique de 1830 à nos Jours. Liège, 1991.

\section{PHILIPPOT, Paul.}

"La Restauration des Sculptures Polychromes",

Studies in Conservation, 15

(1970), (p. 248-252).

\section{PHILIPPOT, Paul.}

"Problèmes esthétiques, et archélogiques de conservation des sculptures polichromes".

Preprints of the Constributions to the New York Conference on "Conservation of Stone and Wooden Objects". 7-13 June 1970, Section Wood (p. 59-62). Ver también: BALLESTREM.A. "Cleaning of Polichromes Sculptures”, ib. idem (p. 69-73).

\section{TAUBERT, J.}

"The Conservation of Wood". Preprints to the Contribution to the New York Conference on "Conservation of Stone and Wooden Objects". 7-13 June 1970, Section Wood (p. 81-85). 